\title{
Christianity and Schizophrenia Redux: An Empirical Study
}

\author{
Szabolcs Kéri ${ }^{1,2,3} \cdot$ Oguz Kelemen ${ }^{4}$
}

(C) Springer Science+Business Media New York 2016

\begin{abstract}
This paper explores the relationship among schizophrenia, spirituality, and Christian religiosity. We interviewed 120 patients with schizophrenia and 120 control individuals $(74.2 \%$ of individuals with self-reported Christian religions). Patients with schizophrenia showed increases in positive spirituality and decreases in positive congregational support, as measured by the Brief Multidimensional Measure of Religiousness/Spirituality. There was no significant difference in Christian religiosity. Higher positive spirituality was predicted by more severe self-disorder, perceptual disorder, and positive clinical symptoms. Schizophrenia patients with religious delusions did not exhibit enhanced Christian beliefs and rituals. These results do not confirm the hypothesis of general hyperreligiosity in schizophrenia.
\end{abstract}

Keywords Schizophrenia $\cdot$ Religion $\cdot$ Spirituality $\cdot$ Christianity $\cdot$ BMMRS $\cdot$ Basic symptoms · Psychotic experiences

\section{Introduction}

From a historical point of view, the relationship between religion and psychiatry was controversial, antagonistic, and sometimes overtly hostile, leading to a strict separation between pastoral care professionals and secular mental health services for more than a

Szabolcs Kéri

szkeri@cogsci.bme.hu

Oguz Kelemen

office.magtud@med.u-szeged.hu

1 Nyírő Gyula Hospital - National Institute of Psychiatry and Addictions, Budapest, Hungary

2 Department of Cognitive Science, Budapest University of Technology and Economics, Egry J. str. 1, Budapest 1111, Hungary

3 Katharina Schütz Zell Center, Budapest, Hungary

4 Department of Behavioral Sciences, University of Szeged, Szeged, Hungary 
century (Koenig 2000). Today the situation is entirely different in many settings, transcending the classic Freudian hypothesis that religion is nothing but a neurotic defense mechanism (Freud 1907/1961; see also Pargament 2002). We have been witnessing the emergence of new bridges between religion and psychiatry, as illustrated in a recent handbook published by the Religion, Spirituality and Psychiatry Section of the World Psychiatric Association (Verhagen et al. 2010). The field of social and clinical psychology has gained a leading role to discover the roots of spirituality and formulate a positive framework even for severe psychological problems (Clark 2010; Gale et al. 2014).

In two seminal papers, Larson et al. $(1986,1992)$ highlighted the paucity of religious variables in psychiatric publications and demonstrated a predominantly favorable impact of religion: $72 \%$ of studies, published between 1978 and 1989, reported a positive relationship between religious involvement and better mental health, $16 \%$ worse mental health, and $12 \%$ no correlation (Larson et al. 1992). Bonelli and Koenig (2013) arrived at the same conclusion by analyzing reports published between 1990 and 2010. Although the positive impact of religion on mental health has been confirmed for several psychiatric disorders (e.g., depression, substance abuse, and suicide), the results are controversial in the case of psychoses such as schizophrenia (Bonelli and Koenig 2013).

According to Mohr and Huguelet (2004), religion may represent a solution to many issues in the life of patients with schizophrenia, but sometimes it is clearly the part of the problem. Some patients with schizophrenia find meaning, empowerment, and inner strength by their religious commitment and community, whereas others experience anxiety, fear, terror, and frustration by spiritual concerns, overvalued ideas, and paranormal experiences. Non-conventional ideas, odd communication, and disorganized behavior may lead to rejection and isolation from the religious community. A core conceptual issue is that spiritual and psychotic experiences (e.g., hearing voices, visions, thought insertion, feeling of influence by a superhuman power) are often difficult to separate and classify, as exemplified by McCarthy-Jones et al. (2013) in the discussion of the tension between modernist and postmodernist approaches to voice-hearing. Menezes and Moreira-Almeida (2010) emphasized that, based on the current diagnostic systems, non-pathological spiritual and religious struggles may seem to be manifestations of a psychotic episode, and the cultural context and meaning must always be taken into consideration to avoid the misinterpretation of normal experiences (Larøi et al. 2014; see also Dein and Cook 2015).

According to Koenig (2007), religious delusions comprise a continuum from reasonable common beliefs to delusional convictions. In his view, new religious movements are not the cause but the consequence of psychosis (Koenig 2007). Murray et al. (2012) went further and presented a theory that Abraham, Moses, Jesus, and St. Paul had had enduring psychotic symptoms and proposed a new diagnostic category for such psychiatric manifestations (grandiose or supraphrenic type of schizophrenia) (Murray et al. 2012). On the other hand, inspired by the phenomenology of Karl Jaspers (1883-1969) and the theology of Rudolf Bultmann (1884-1976), Ronald D. Laing (1927-1989) claimed that the seemingly odd thinking of schizophrenia patients communicates existential truths and schizoid withdrawal can be considered as a form of modern Stoicism (for a historical review, see Miller 2009).

Although the connection between religiousness and psychosis has been extensively documented by eminent historical personalities of psychiatry, such as Phillipe Pinel (1745-1826) and Emil Kraepelin (1856-1926), today's consensus is that religion is not an etiologic factor in schizophrenia (Wilson 1998). However, in a provocative paper, Littlewood and Dein (2013) directly addressed the question whether Christianity can cause 
schizophrenia. By applying the agenda of evolutionary psychology and cognitive science, they defined six aspects of Christianity that may contribute to the transformation of transient psychotic states to schizophrenia: an omniscient deity, a decontextualized self, an ambiguous agency, a downplaying of immediate sensory data, and a scrutiny of the self and its reconstitution in conversion (Littlewood and Dein, 2013). The core hypothesis comprises the presence of a hidden and immaterial self that communicates with an omniscient and omnipotent entity who controls thoughts, emotions, and acts. During Christian conversion, the old self is disassembled, and a new one is born. The final shift and rebirth are attributed to the omniscient entity of God, accompanied by an enhanced conscious self-awareness and the scrutiny of the self. The attribution of agency and control ("Is it me who is acting or a supernatural entity?") is an integral and common mechanism of both religion and psychosis (Dein and Littlewood 2011). The attribution of primary agency is withdrawn from the external world and the old identity of the self, which has been destroyed by religious conversion. The result is estrangement from experience, downplaying of everyday sense data, and enhanced reflexive self-consciousness (hyperreflexivity and hyper-intentionality), which are essential aspects of schizophrenia according to classic and upgraded psychopathological models (Jaspers 1913; Mishara et al. 2014; Nelson et al. 2014a, b; Sass 2001; Sass and Parnas 2003). However, similar mechanisms can be observed in several other organized religions where agency is attributed to a deity and cults where agency is given over to a charismatic leader (Silverstein 1988). Therefore, it is dubious to link these processes specifically to Christianity. Furthermore, it is an open question whether it is the self-disorder that contributes to attraction to, and resonance of, religious ideas, or religious ideas themselves contribute to psychosis.

Self-disorder (Ichstörungen) may provide a unique insight into the subjective experiences of patients, including psychic and somatic depersonalization, "mirror" phenomenon (an impression of a change in one's mirror image), and an experience in discontinuity in own action (faulty perception of agency) (Huber et al. 1979; Klosterkötter 1988; Klosterkötter et al. 1996, 2001). When the integrity of the self is lost, the origin of sensations, feelings, thoughts, and actions is easily attributed to supernatural entities.

Using a qualitative case analysis, Bhargav et al. (2015) demonstrated that both spiritually advanced people and patient with psychosis exhibit alterations in their sense of self. In their view, the most significant difference is that psychotic experiences are characterized by the disruption of the self (e.g., lack of sense of self, thoughts questioning the existence of the patient, social withdrawal, and inability to continue any occupation), whereas in spiritual transformations a gradual thinning out of the selfish ego can be observed, and eventually individual consciousness merges into universal consciousness (Bhargav et al. 2015; see also Jackson and Fulford 1997; Stanghellini and Fusar-Poli 2012). Although, in accordance with the original principles of William James (1902), Bhargav et al. (2015) contrasted sudden and fulminant psychosis with gradual conversion, many people have sudden religious conversion experiences and many individuals with psychosis experience a gradual development of the symptoms. The suddenness or gradualness of the conversion is related to the cultural norms regarding the most valid way to become religious at any place and time (Silverstein 1988).

If it is true that the crucial psychological mechanism is a unique kind of altered selfawareness in both Christianity and schizophrenia (Littlewood and Dein 2013), we might expect a connection between Christian religious experiences and schizophrenic self-disturbance. Before investigating this question, it is essential to differentiate and define distinct dimensions of religion and spirituality in the context of the present study (Oman 2013; Taves 2009). The Brief Multidimensional Measure of Religiousness/Spirituality 
(BMMRS) is one of the most comprehensive instruments including three general areas: spiritual experiences (i.e., a personal feeling of connection to a higher power/God), religious practices (i.e., culturally established behavior and activity), and congregational support (i.e., social support provided by the fellows in the religious community) (Fetzer Institute and the National Institute on Aging 1999; Johnstone et al. 2009). Note that the BMMRS is not specifically focused on Christian spirituality and religion. For example, by changing the term "God" to "higher power," BMMRS is suitable for the assessment of individuals with different faith traditions including Buddhism (Johnstone et al. 2012b). In a nation-wide Swiss sample based on the "Religion et lien social" survey (Campiche and Dubach 1992), Stolz (2008) identified Christianity (i.e., the frequency of Christian prayers and religious services; beliefs that God exists and that He has shown himself in Jesus Christ) and alternative religiosity/spirituality (i.e., beliefs in astrology, luck charms, future tellers, and reincarnation) as two orthogonal constructs in factor analytic models (nonChristian organizational religions were excluded from the analysis and ethnicity did not contribute to Christianity or alternative religiosity/spirituality) (Stolz 2008). Therefore, it is essential to examine whether any differences in religiosity/spirituality between schizophrenia patients and non-clinical individuals with self-declared Christian religions are specifically related to Christianity or not.

Based on the above-discussed findings and theories, the present study addressed the following hypotheses:

Hypothesis 1 Patients with schizophrenia with self-reported Christian religion, as compared with non-clinical individuals, exhibit increased spirituality and religiosity, with a particular reference to Christian beliefs and practices. This hypothesis is addressed in the framework of the BMMRS dimensions and Stolz's definition of Christianity.

Hypothesis 2 Increased spiritual/religious experiences and behavior can be significantly explained by schizophrenia-associated self-disorder in contrast to other subjective psychotic experiences (diminished affectivity, disturbed contact, perplexity, cognitive disorder, cenesthesias, and perceptual disorder).

\section{Methods}

\section{Participants}

In total, 120 patients with DSM-IV (Diagnosis and Statistical Manual of Mental Disorders, 4th edition) schizophrenia (American Psychiatric Association 1994) and 120 non-clinical individuals participated in the study. The patients were recruited at three psychiatric centers in North and South Hungary. The control individuals were enrolled via the internet and personal advertisement. We recruited control individuals with similar age, gender, and education to that of the patients with schizophrenia, given that these sociodemographic parameters may be related to religiousness (Stolz 2008) (Table 1). Inclusion criteria for the patients were: (i) stabilized clinical state, (ii) ability and willingness to participate and give informed consent, and (iii) no changes in medications at least for four weeks (mean chlorpromazine-equivalent dose of antipsychotics: $445 \mathrm{mg} /$ day, $S D=275.3$ ). All participants were screened with the Mini-International Neuropsychiatric Interview (Sheehan et al. 1998) and received a neurological examination, EEG, head magnetic resonance imaging, and blood and urine tests including the monitoring of psychoactive substances. 
Table 1 Demographic characteristics of the participants

\begin{tabular}{lll}
\hline & Patients with schizophrenia $(N=120)$ & Non-clinical individuals $(N=120)$ \\
\hline Age (years) & $39.6(13.0)$ & $39.1(12.9)$ \\
Gender (male/female) & $63 / 57$ & $63 / 57$ \\
Education (years) & $10.9(2.7)$ & $10.4(2.9)$ \\
Religions & & \\
Roman Catholic & $63(52.5 \%)$ & $63(52.5 \%)$ \\
Protestant & $26(21.7 \%)$ & $26(21.7 \%)$ \\
Unaffiliated & $25(20.8 \%)$ & $25(20.8 \%)$ \\
Other & $6(5.0 \%)$ & $6(5.0 \%)$ \\
\hline
\end{tabular}

In the case of age and education, data are mean (standard deviation, SD). Religion refers to the number (\%) of individuals according to self-identification. Given that the two groups were matched, two-tailed $t$ tests and Chi-square tests did not indicate differences $(p s>0.5)$

Patients with psychoactive substance misuse were excluded. The clinical symptoms were characterized by the Positive and Negative Syndrome Scale (PANSS) (Kay et al. 1987), whereas the subjective experiences related to psychosis were evaluated by the Bonn Scale for the Assessment of Basic Symptoms (BSABS) (Gross et al. 2008). Based on the MiniInternational Neuropsychiatric Interview and PANSS, we observed religious delusions in 14 patients $(11.7 \%)$. The demographic and clinical variables are presented in Table 1.

\section{Ethics Statement}

The study was done in accordance with the Declaration of Helsinki. The procedure was approved by the institutional ethics committee. All participants gave written informed consent.

\section{Brief Multidimensional Measure of Religiousness/Spirituality (BMMRS)}

The BMMRS is a self-report instrument comprising items with Likert-like scales. Lower scores indicate a greater degree of religiosity and spirituality (Table 2). The scale focuses on three main areas: spiritual experiences (i.e., a personal feeling of connection to a higher power), religious practices (i.e., culturally established behavior and activity), and congregational support (i.e., social support provided by the fellows in the religious community) (Fetzer Institute and the National Institute on Aging 1999). We adopted the reconceptualized factor structure of the BMMRS: (1) positive and negative spiritual experiences (positive and negative emotional experiences of connectedness with a higher power/the universe/God), (2) forgiveness (a specific coping strategy of forgiving others/ oneself and being forgiven by a higher power/God), (3) cultural-religious practices (prayers, rituals, and religious services), (4) positive and negative congregational support (support or rejection by the religious community) (Table 2) (Johnstone et al. 2009).

Given that self-report scales show inherent limitations in psychotic patients, we used a cross-validation procedure in 25 patients who also participated in an in-depth narrative and clinical interview (average duration: $3.5 \mathrm{~h}$ in $2-3$ sessions). The interviewer, who was blind to the aims of the study, rated each BMMRS dimension on a 1-5 scale. These scores were correlated with the BMMRS self-rating results. All correlations between the interviewer's scores and the self-report scores were definitive $(r \mathrm{~s}>0.7)$. 
Table 2 The factor structure of the Brief Multidimensional Measure of Religiousness/Spirituality (BMMRS) (Johnstone et al. 2009)

\begin{tabular}{|c|c|c|c|}
\hline Subscales & Sample items & $\begin{array}{l}\text { Number } \\
\text { of items }\end{array}$ & $\begin{array}{l}\text { Cronbach } \\
\text { alpha }\end{array}$ \\
\hline $\begin{array}{l}\text { Positive spiritual } \\
\text { experiences }\end{array}$ & $\begin{array}{l}\text { "I find strength and comfort in my religion." } \\
\text { "I believe in a higher power/God who watches over me." }\end{array}$ & 15 & 0.92 \\
\hline $\begin{array}{l}\text { Negative spiritual } \\
\text { experiences }\end{array}$ & $\begin{array}{l}\text { "I feel I am being punished by a higher power for my } \\
\text { sins or lack of spirituality." } \\
\text { "I wonder whether I have been abandoned by a higher } \\
\text { power/God." }\end{array}$ & 2 & 0.87 \\
\hline Forgiveness & $\begin{array}{l}\text { "I know that I am forgiven by a higher power." } \\
\text { "I have forgiven those who hurt me." }\end{array}$ & 5 & 0.80 \\
\hline $\begin{array}{l}\text { Cultural-religious } \\
\text { practices }\end{array}$ & $\begin{array}{l}\text { "How often do you go to religious services?" } \\
\text { "How often do you read the Bible or other religious } \\
\text { literature?" }\end{array}$ & 5 & 0.80 \\
\hline $\begin{array}{l}\text { Positive } \\
\text { congregational } \\
\text { support }\end{array}$ & $\begin{array}{l}\text { "If you had a problem or were faced with a difficult situation, } \\
\text { how much comfort would the people in your congregation } \\
\text { be willing to give you?" } \\
\text { "If you were ill, how much would the people in your } \\
\text { congregation help you out?" }\end{array}$ & 2 & 0.64 \\
\hline $\begin{array}{l}\text { Negative } \\
\text { congregational } \\
\text { support }\end{array}$ & $\begin{array}{l}\text { "How often do the people in your congregation make too } \\
\text { many demands on you?" } \\
\text { "How often are the people in your congregation critical of } \\
\text { you and the things you do?" }\end{array}$ & 2 & 0.61 \\
\hline
\end{tabular}

The items were scored on a 0 (maximum, e.g., strongly agree)-to- 3 (minimum, e.g., strongly disagree) scale (Johnstone et al. 2009). Lower scores indicate higher levels of spirituality and religiousness

\section{Definition of Christian Spirituality and Religiousness}

There were four items to measure Christian religiosity (Stolz 2008): (1) importance of Christian religion in general, (2) frequency of Christian prayers, (3) frequency of Christian religious service, and (4) belief that God exists and that He has shown himself in Jesus Christ. All items were scored by the participants on a 1-5 scale (1-maximum, 5-minimum). This self-report scale was also confirmed by an independent interview as described in the case of the BMMRS.

\section{Bonn Scale for the Assessment of Basic Symptoms (BSABS)}

The BSABS is a detailed semistructured interview to evaluate subjective experiences related to psychosis, that is, the assessor is interested in how individuals with psychosis experience changes in their mental processes (perception, attention, emotions, and thinking) and social life (Gross et al. 2008). The items are classified according to Parnas et al. (2003) and our previous study (Szily and Kéri 2009): 1. diminished affectivity (4 items, e.g., diminished initiative and dynamism, anhedonia, diminished feelings of others, diminished need for interpersonal relations); 2. disturbed contact (13 items, e.g., lack of ability for interpersonal contact, vulnerability to interpersonal contact, inability to tolerate crowd, increased impressionability by others' behavior, increased impressionability by others' suffering); 3. perplexity (11 items, e.g., ambivalence, inability to discriminate between own feelings, hyper-reflectivity/loss of naturalness, disturbed receptive language, 
inability to re-visualize, inability to understand symbols, inability to grasp significance of perception, heightened perception, captivation of attention by perceptual detail, derealization: strangeness and intrusive perception); 4. cognitive disorder (6 items, e.g., thought interference, thought pressure, thought block, successive thought block and thought interference, disorder of expressive language, diminished thought initiative and goal-directedness of thinking); 5. self-disorder (4 items, e.g., psychic depersonalization, somatic depersonalization, "mirror" phenomenon, e.g., impression of a change in one's mirror image, experience of discontinuity in own action); 6. cenesthesias (4 items, e.g., electrical bodily sensations, sensation of movement, pressure or pulling on the body or on the body surface, sensations of lightness, heaviness, levitation, falling, constriction, dilatation, shrinking, or expansion of the body); 7. perceptual disorder (13 items, e.g., unclear seeing, partial sight, photopsia, micro-macropsia, meto-chromopsia, changes in perception of others' faces or figures, skewed sight/disturbed perspective, disturbed sense of distance, disturbed rectilinearity, dysmegalopsia, abnormal persistence of visual irritation). Each item is coded as 0 (the subjective experience indicated by the item is not present) and 1 (the subjective experience indicated by the item is present). Altogether, there are 55 items (total score range 0-55). Higher scores indicate more pronounced subjective experiences related to psychosis. The assessment was performed by two independent persons who participated in a series of training sessions held by an expert with an extensive experience with the BSABS. The mean kappa reliability coefficient for single items was 0.71 between the two raters.

\section{Positive and Negative Syndrome Scale (PANSS)}

In the PANSS, the patient is rated from 1 to 7 on 30 different symptoms present in schizophrenia and other psychotic disorders. In contrast to the BSABS, the PANSS gives information about the observable and verbally accessible psychiatric symptoms. Higher scores indicate more severe clinical symptoms. There are 7 items for positive symptoms (e.g., delusions, hallucinations, and conceptual disorganization), 7 items for negative symptoms (e.g., blunted affect, emotional withdrawal, and passive/apathetic social withdrawal), and 16 items for general psychopathology (e.g., anxiety, somatic concerns, guilt feelings, and depression). The mean kappa reliability coefficient for single items was 0.84 between the two trained raters.

\section{Data Analysis}

We used STATISTICA 12 software package (StatSoft, Tulsa, USA). All raw data were checked for Gaussian distribution by Kolmogorov-Smirnov tests to select parametric or nonparametric tests for further analysis. Kruskal-Wallis tests followed by multiple comparisons of mean ranks for all groups were conducted to compare schizophrenia patients with or without religious delusions and non-clinical individuals on the Stolz's Christianity and BMMRS measures. Spearman's correlation coefficients were calculated between the Stolz's Christianity/BMMRS and the BSABS/PANSS scores. We also conducted hierarchical regression analyses to determine the predictors of spiritual and religious experiences. The level of statistical significance was set at $\alpha<0.05$. We used False Discovery Rate (FDR) corrections for multiple comparisons (Benjamini 2010). 


\section{Results}

\section{Christian Religiousness and BMMRS in Schizophrenia}

Table 3 depicts the Stolz's Christianity and BMMRS scores, together with the results of the Kruskal-Wallis tests. Figure 1 depicts the standardized Stolz's Christianity/BMMRS scores to visualize the differences between schizophrenia patients with and without religious delusions and non-clinical individuals. We observed enhanced positive spirituality and decreased positive congregational support in patients with schizophrenia relative to non-clinical individuals. The schizophrenia patients with religious delusions exhibited higher positive spirituality than the patients without religious delusions. There were no significant between-groups differences in Christian religiousness, BMMRS negative spirituality, forgiveness, religious-cultural practices, and negative congregational support (Table 3; Fig. 1). The Stolz's Christian religiosity index was not related to positive spirituality $(R=0.06, p>0.2)$.

\section{Can Psychotic Experiences and Clinical Symptoms Predict Spirituality and Religiousness?}

Table 4 summarizes the PANSS and BSABS scores. Table 5 depicts Spearman's correlation coefficients between spirituality/religiousness scores and clinical scales. There were several significant correlations that survived corrections for multiple comparisons: Higher positive spirituality was associated with more severe self-disorder, perplexity, perceptual disorder, and positive symptoms. Higher negative spirituality was associated with more severe self-disorder, perceptual disorder, and positive symptoms. We also found that the schizophrenia patients with religious delusions displayed more severe self-disorder than the patients without religious delusions (Table 4).

We conducted multiple regression analyses with the Stolz's Christian religiousness and BMMRS scores as dependent variables and the PANSS/BSABS scores as independent variables. The analyses were controlled for age, gender, and education.

In the first step, we investigated if demographic variables (age, gender, education) predicted BMMRS scores. The demographic variables did not predict the BMMRS scores $\left(-0.1<\beta \mathrm{s}<0.1, p \mathrm{~s}>0.2, R^{2}<0.1\right)$.

In step two, the PANSS/BSABS scores were included in the regression model to investigate whether the clinical symptoms added a significant predictive value. We found that positive spirituality was predicted by self-disorder $(\beta=-0.21$, partial correlation: $\left.-0.19, R^{2}=0.44 ; t(108)=-1.99, p<0.05\right)$, perceptual disorder $(\beta=-0.23$, partial correlation: $\left.-0.24, R^{2}=0.24 ; t(108)=-2.56, p<0.05\right)$, and positive symptoms $\left(\beta=-0.23\right.$, partial correlation: $\left.-0.24, R^{2}=0.21 ; t(108)=-2.53, p<0.05\right)$. The full model: $F(11,108)=4.70, p<0.001, R^{2}=0.32$. Negative spirituality was predicted by perceptual disorder $\left(\beta=-0.23\right.$, partial correlation: $-0.22, R^{2}=0.24 ; t(108)=-2.37$, $p<0.05$; full model: $\left.F(11,108)=2.55, p<0.05, R^{2}=0.21\right)$. There were no additional clinical predictors of the Stolz's Christian religiousness and BMMRS scores $\left(-0.2<\beta \mathrm{s}<0.2, p \mathrm{~s}>0.1, R^{2}<0.1\right)$. 


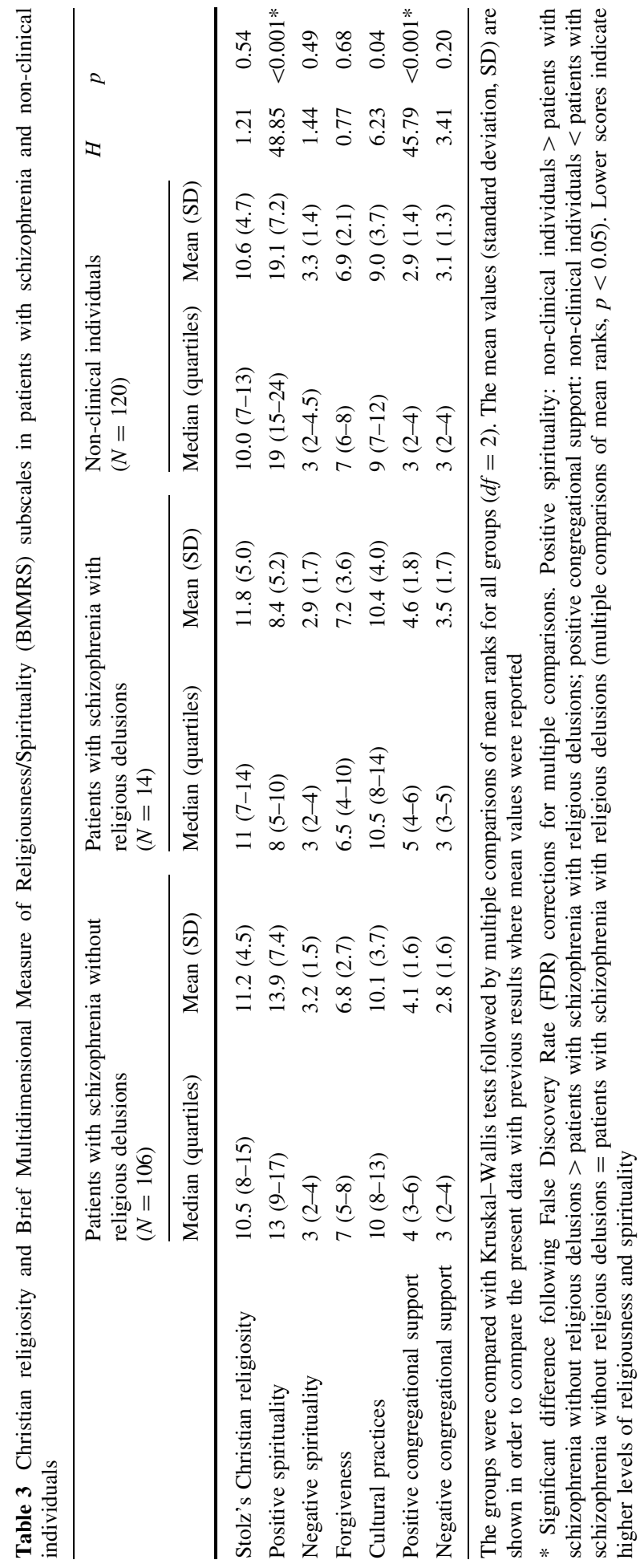


Fig. 1 Normalized scores on the Brief Multidimensional Measure of Religiousness/Spirituality (BMMRS) and Stolz's

Christianity index. Patients with schizophrenia were characterized by significantly higher positive spirituality and lower positive congregational support as compared to non-clinical individuals. The patients with religious delusions showed even higher positive spirituality than the patients without religious delusions. Lower scores indicate higher levels of religiousness and spirituality

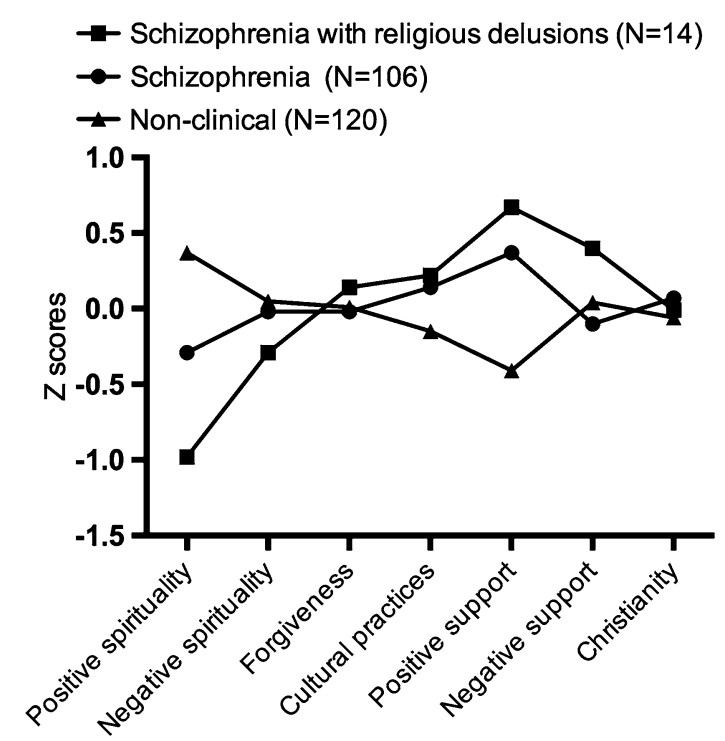

Table 4 Clinical characteristics of the patients with schizophrenia

\begin{tabular}{|c|c|c|c|c|}
\hline & \multicolumn{2}{|c|}{$\begin{array}{l}\text { Patients with } \\
\text { schizophrenia }(N=106)\end{array}$} & \multicolumn{2}{|c|}{$\begin{array}{l}\text { Patients with schizophrenia with } \\
\text { religious delusions }(N=14)\end{array}$} \\
\hline \multicolumn{5}{|c|}{ Positive and Negative Syndrome Scale (PANSS) } \\
\hline Positive symptoms & $18.3(6.2)$ & & $19.7(9.3)$ & \\
\hline Negative symptoms & $22.4(8.7)$ & & $24.1(9.6)$ & \\
\hline \multirow[t]{2}{*}{ General symptoms } & $42.6(9.2)$ & & $40.8(11.4)$ & \\
\hline & Median (quartiles) & Mean (SD) & Median (quartiles) & Mean (SD) \\
\hline \multicolumn{5}{|c|}{ Bonn scale for the assessment of basic symptoms (BSABS) } \\
\hline Self-disorder* & $1(1-2)$ & $1.5(1.2)$ & $3(2-4)$ & $2.6(1.3)$ \\
\hline Perplexity & $3(2-5)$ & $3.5(1.5)$ & $4(3-5)$ & $3.9(2.2)$ \\
\hline Perceptual disorder & $2(1-3)$ & $2.1(1.4)$ & $2(1-3)$ & $2.2(1.7)$ \\
\hline Diminished affectivity & $2(2-3)$ & $2.3(1.3)$ & $2(1-3)$ & $1.9(1.4)$ \\
\hline Disturbed contact & $3(2-4)$ & $2.7(1.5)$ & $2(1-3)$ & $2.4(1.6)$ \\
\hline Cognitive disorder & $2(2-4)$ & $2.6(1.4)$ & $3(2-4)$ & $2.9(1.6)$ \\
\hline Cenesthesias & $1(1-2)$ & $1.4(0.9)$ & $2(1-2)$ & $1.5(1.1)$ \\
\hline
\end{tabular}

The PANSS scores are mean values (standard deviation, SD). The BSABS scores are median values (lowerupper quartiles). The mean values are also shown for the BSABS scores in order to compare the present data with previous results where mean values were reported

* Significant difference between patients with and without religious delusions following False Discovery Rate (FDR) corrections for multiple comparisons (Mann-Whitney $U$ test, $Z=-2.92, p=0.003$ ) 


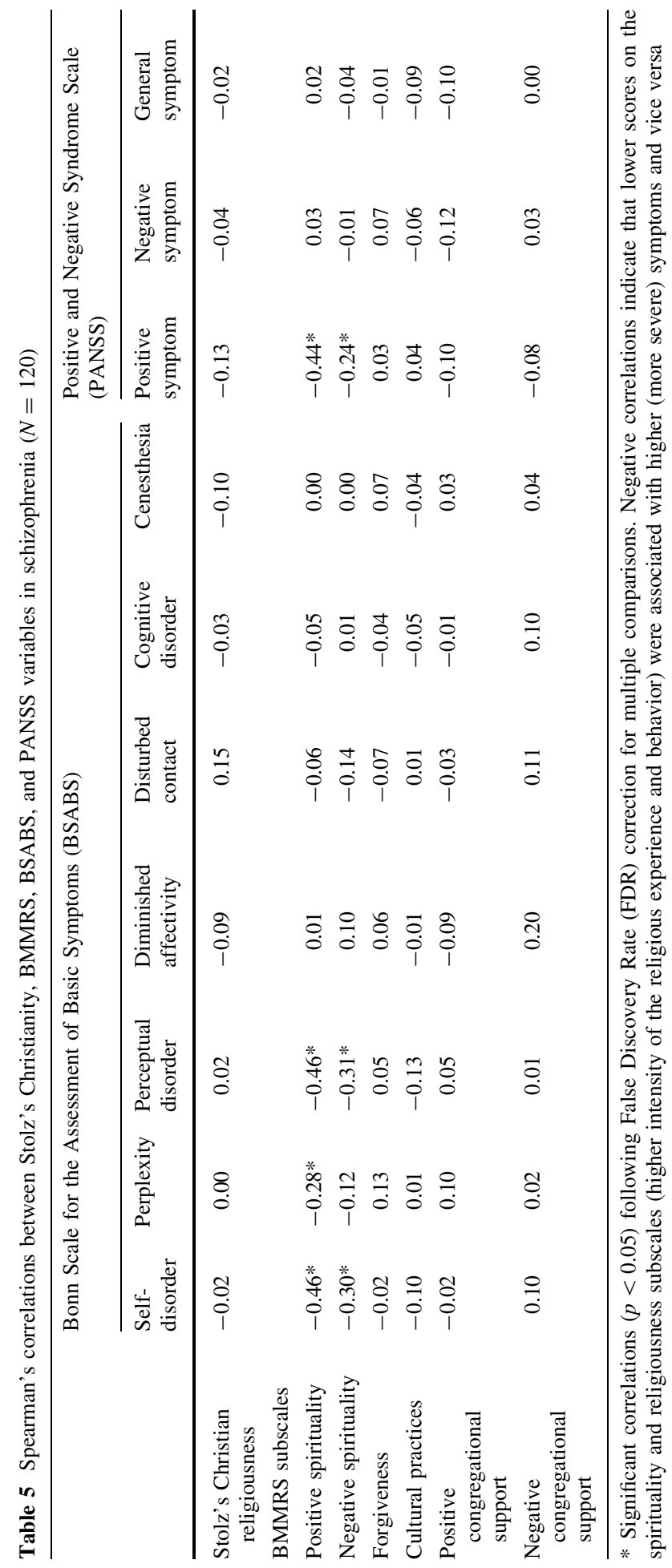




\section{Discussion}

\section{Christian Hyper-religiosity in Schizophrenia?}

Our initial hypotheses were not fully supported by the data: We did not find evidence for a general hyper-religiosity in schizophrenia. The characteristics of spiritual and religious experiences and behavior of patients with schizophrenia displayed a specific pattern with both increased and decreased functions: Positive spirituality was enhanced, and positive congregational support was weakened. It is important to note that the two items of negative spirituality ("I feel I am being punished by a higher power for my sins or lack of spirituality."; "I wonder whether I have been abandoned by a higher power.") were from the religious/spiritual coping dimension of the BMMRS, describing a spiritual struggle with guilt and alienation. This is characteristic of some patients with depression (Exline et al. 2000), but, according to the present data, not definitely for patients with schizophrenia. Nevertheless, negative spirituality was associated with more severe self-disorder, perceptual disorder, and positive symptoms in the correlation analysis, but only perceptual disorder was a significant predictor. It is an important finding that patients with schizophrenia differed from the control participants regarding increased positive but not negative spirituality, which suggests that their enhanced spirituality was not disruptive, frightening, or directly paranoia-inducing. Mohr et al. (2010a) documented positive religious changes in $20 \%$ of patients with schizophrenia during a 3-year follow-up period, which represented a significant transformation of negative religious themes to positive ones. Almost every second patient experienced that spirituality and religion helped them cope with their illness (Mohr et al. 2010b).

We observed a relatively limited number of patients with religious delusions (14 out of 120, $11.7 \%$ ). These patients displayed even higher positive spirituality than the patients without religious delusions, but they scored similarly on other measures of spirituality/ religiousness. In a comparable sample of patients with schizophrenia, Siddle et al. (2002) found that $24 \%$ of the participants had religious delusions, which were associated with higher PANSS scores (more severe symptoms) and worse clinical outcome. In other studies, the occurrence of disruptive religious delusions was less definitive, and private and public religious activities played a significant role in the life of many patients (Gearing et al. 2011; Huguelet et al. 2006; Kroll and Sheehan 1989; Mohr et al. 2006, 2012; Nolan et al. 2012). Overall, the prevalence of religious delusions displayed a large variety across studies (6-63.3\%) (Grover et al. 2014).

The themes of the delusions were similar to that reported in the literature, including persecution and being controlled by supernatural powers and grandiosity (Mohr et al. 2010b). Delusions of sin and guilt were not frequent and dominant. The increased positive spirituality in deluded patients is consistent with the view that these individuals valued religion more than non-deluded ones, but they received less support from their religious communities (Mohr et al. 2010b). Religious delusions are often focused on spiritual identity, spiritual figures, and the personal meaning of the illness. Some of these beliefs reflect the struggle of the patients to reconstruct their relationship with the world and other people, whereas others reflect a complete loss of connection with the outside reality (Rieben et al. 2013).

Kirov et al. (1998) concluded that the experience of psychosis may lead to increases in religiosity, which is an important coping mechanism for many patients. However, a careful consideration of the literature revealed that religion can produce both advantageous and 
disadvantageous effects, depending on the type of clinical symptoms and the cultural influences (Gearing et al. 2011). In this respect, the issue of causality has not been convincingly determined. For example, a person with emerging psychosis-like experiences who turns to religion for a sense of identity and explanations for aberrant experiences may indeed become more psychotic, but this may have nothing to do with religion per se; the same person might, in the absence of religious preoccupation, become immersed in other non-religious belief systems to a maladaptive degree.

Surprisingly, Cohen et al. (2010) found that elderly individuals with schizophrenia had significantly lower levels of religiousness than their age peers, with a particular reference to less frequent religious attendance. In general, religiousness was not significantly associated with psychotic symptoms, and it had a modest additive effect on the quality of life (Cohen et al. 2010). Many aspects of the discrepant findings can be attributed to basic methodological issues: Most of the studies investigated religiousness as a secondary measure, clear definitions were not presented, and different instruments were used for the assessment of diverse aspects of religiousness and spirituality (Oman 2013). By using the BMMRS, which is a conceptually well-established and validated instrument, we demonstrated that the feelings of connection to a higher power or God were increased in schizophrenia, whereas socially defined religious practices and congregational support were reduced. The latter was true for positive congregational support, but the patients did not experience a marked negative social discrimination in their religious community (negative congregational support).

An important aspect of our study is that these findings were independent of Christianity. Indeed, patients with schizophrenia and non-clinical individuals exhibited similar scores on the Christian religiousness measure, and it was true even for patients with religious delusions. Religious delusions were dogmatically loose and diverse, often with idiosyncratic and incoherent contents. These delusions were not associated with a strengthened Christian faith, that is, the patients did not feel that their religion became more salient, did not practice religious rituals more frequently, and did not report enhanced Christian beliefs (i.e., the God exists and that He has shown himself in Jesus Christ). The independence of enhanced spirituality from Christianity is especially remarkable because the declared religion of the majority of our patients was either Roman Catholic or Protestant. This suggests that psychosis-related spiritual/religious phenomena are not necessarily related to past religious socialization.

It is essential to emphasize that we did not use the Stolz's Christianity scale to discriminate people by their religion. It was designed to measure the intensity of beliefs, values, and practices specifically related to Christianity. The inclusion of the Stolz's scale was necessary to assess the relationship between schizophrenia, Christianity, and more general aspects of spirituality and religious practice as measured by the BMMRS.

\section{Religion and Psychotic Experiences}

Regarding the connection between psychotic experiences and spirituality/religiousness, our hypothesis was partially supported: As expected, self-disorder was a significant predictor, but it was confined to positive spirituality (a mixture of items from daily spiritual experiences, meaning/purpose in life, values/beliefs, and religious/spiritual coping dimensions of the original BMMRS) (Johnstone et al. 2009). Notably, schizophrenia patients with religious delusions displayed a more severe self-disorder as compared to patients without religious delusions, which was a quite circumscribed clinical difference (i.e., religiously deluded and non-deluded patients were characterized by similar PANSS scores and 
BSABS items different from self-disorder). In contrast, perceptual disorder was a significant predictor of both positive and negative spirituality.

It is important to take into account that the BSABS self-disorder, perceptual disorder, and perplexity dimensions are strongly interconnected phenomena with potentially overlapping mechanisms. Faulty temporal integration and incoherence in the perceptual system may result in disturbed self-experiences including depersonalization, decreased sense of agency, and the disintegration of thoughts, feelings, and behavior (Postmes et al. 2014; Sass and Parnas 2003). Matussek (1987) noted that alterations in perceptual experience could lead to feelings that the self and the world are changing, which could then result in the generation of explanatory beliefs including apocalyptic delusions. Several studies suggested that increased spirituality was related to a decreased focus on the self, which was associated with right parietal lobe dysfunction, a key area for attention, perceptual integration, and self-representation (Decety and Chaminade 2003; Robertson 2003; Johnstone et al. 2012a, 2015). The dysfunction of the parietal lobe may also be important in schizophrenic self-disorder (Brent et al. 2014).

In some cases, the roots of perceptual anomalies can be explored at the level of very basic mechanisms, such as the visual pathways originating in the retina, the perception of contrast and motion, and the Gestalt organization of low-level environmental stimuli (Kéri et al. 2005; for a review, see Silverstein and Rosen 2015). It is of particular interest how these basic perceptual mechanisms can be integrated with very distinct psychopathological models, such as the Jungian concept of self and psychosis (Silverstein 2007, 2014). In the present study, we demonstrated that perceptual disorder may contribute to personal spiritual experiences and a sense of deeper transpersonal meaning and purpose of life, but not to other aspects of spirituality and religiousness. The circumscribed contribution of psychopathological phenomena to certain aspects of spirituality may be a possible explanation why some studies found associations between spirituality/religiousness and psychotic symptoms, whereas others failed to do so (Gearing et al. 2011; Grover et al. 2014). The key is the proper and consistent definition and assessment of spiritual/religious dimensions (Hill 2013).

Dein and Littlewood (2011) postulated a common evolutionary and cognitive mechanism of psychosis and religious cognition. The starting point was a classic psychopathological interpretation (Jaspers 1913), claiming that schizophrenia and enhanced religious experiences are both linked to the dissolution of the border between the self and others (disruption of the "ego-boundary"). In this view, the first mechanism that binds or separates self and others is the detection of intentional agents. Humans have a hyperactive agent detection template by which we can seek out and find entities with intentions and plans beyond the self and the mind of other people (e.g., gods, angels, and ghosts) (Atran 2002; Barrett 2000; Boyer 2001). Agency, however, is not everything. Gods and other supernatural agents have thoughts, plans, emotions, and desires. They have a complex mental representation of the world. By using our theory of mind abilities, we attribute mental states not only to the self and the inner world of other people but also to "minds without material bodies," a kind of description for invisible agents (Bloom 2004). Altogether, agency detection and theory of mind (agency description) both contribute to the opening of the gate between the self and others, a key element in both religious cognition and psychosis (Dein and Littlewood 2011). The present study added a more bottom-up approach to these high-level theories, namely the importance of perceptual functions in the emergence of self-experience and its contribution to spirituality.

We found that patients with religious delusions displayed a pronounced self-disorder. According to Blankenburg (1971; discussed by Sass and Parnas 2003), a key feature of 
self-disorder is the loss of natural self-evidence and common sense, which is associated with social withdrawal, inner hyper-reflexivity, and hyper-intentionality. Psychotic patients withdrawn from their social environment may experience an enhanced reflexive awareness in which percepts, actions, and structures of the external and internal world gain an unusual level of awareness; in everyday cognition, these are out of the field of reflexive awareness, presupposed, taken for granted, or simply remain unnoticed (Sass and Parnas 2003). In some cases, enhanced reflexivity may be important in the creative restructuring of the selfworld relationship and spiritual development (Clark 2010).

\section{Limitations and Future Directions}

The most important limitation is that the study was cross-sectional and correlational. Mohr et al. (2010a) demonstrated that spirituality/religiousness is labile in many patients with schizophrenia. In the current sample, we have no information how spirituality/religiousness may change along with decreases and increases in psychotic symptoms and vice versa. The study included only a small number of patients with religious delusions.

We did not measure general health, quality of life, and clinical outcome. It remains to be clarified how the dimensions of spirituality/religiousness are related to the prognosis of the illness and how different social factors may modify it. A critical question is why patients with schizophrenia receive less congregational support and what kind of psychosocial intervention can be used to facilitate the patients' integration into their religious community. Individuals with psychosis wishing to engage in communal religious experiences who then feel ostracized or stigmatized due to their odd appearance or behavior could internalize stigma, develop depression, lose hope, and must face with social rejection and isolation.

In some cases, psychosis is a transformative crisis with a chance of development, which should not be medicalized and stigmatized (Clark 2010). Rejection, guilt, and uselessness may further worsen desperation and paranoid symptoms, leading to personal suffering, decreased quality of life, and worse clinical outcome. However, negative congregational support was not verified in the present study. A major challenge for pastoral care providers and mental health professional is to overcome the issues discussed above and to achieve a better integration of individuals with psychosis according to their needs, empowerment, and realistic opportunities.

Acknowledgments We thank Ibolya Halász, Katalin Kaza, and Péter Nagy for their assistance in the clinical interviews. We are indebted to two anonymous reviewers for their comments and suggestions.

\section{Compliance with Ethical Standards}

Conflict of interest The authors declare no conflict of interest.

\section{References}

American Psychiatric Association. (1994). DSM-IV: Diagnostic and statistical manual of mental disorders (4th ed.). Washington, DC: Author.

Atran, S. (2002). In gods we trust: The evolutionary landscape of religion. Oxford: Oxford University Press. Barrett, J. (2000). Exploring the natural foundations of religion. Trends in Cognitive Sciences, 4, $29-34$.

Benjamini, Y. (2010). Discovering the false discovery rate. Journal of the Royal Statistical Society: Series B (Statistical Methodology), 72, 405-416.

Bhargav, H., Jagannathan, A., Raghuram, N., Srinivasan, T. M., \& Gangadhar, B. N. (2015). Schizophrenia patient or spiritually advanced personality? A qualitative case analysis. Journal of Religion and Health, 54, 1901-1918. (Erratum in: Journal of Religion and Health 2015, 54, 1919-1920). 
Blankenburg, W. (1971). Der Verlust der Natiirlichen Selbstverstdndlichkeit: Ein Beitrag zur Psychopathologie Symptomarmer Schizophrenien. Stuttgart: Ferdinand Enke Verlag.

Bloom, P. (2004). Descartes' baby. New York, NY: Basic Books.

Bonelli, R. M., \& Koenig, H. G. (2013). Mental disorders, religion and spirituality 1990 to 2010: A systematic evidence-based review. Journal of Religion and Health, 52, 657-673.

Boyer, P. (2001). Religion explained. London: Heineman.

Brent, B. K., Seidman, L. J., Thermenos, H. W., Holt, D. J., \& Keshavan, M. S. (2014). Self-disturbances as a possible premorbid indicator of schizophrenia risk: A neurodevelopmental perspective. Schizophrenia Research, 152, 73-80.

Campiche, R., \& Dubach, A. (1992). Croire en Suisse(s). Lausanne: Éditions l'Age d'Homme.

Clark, I. (2010). (ed.) Psychosis and spirituality. Consolidating the New Paradigm. West Sussex: Wiley

Cohen, C. I., Jimenez, C., \& Mittal, S. (2010). The role of religion in the well-being of older adults with schizophrenia. Psychiatric Services, 61, 917-922.

Decety, J., \& Chaminade, T. (2003). When the self represents the other: A new cognitive neuroscience view on psychological identification. Consciousness and Cognition, 12, 577-596.

Dein, S., \& Cook, C. C. H. (2015). God put a thought into my mind: The charismatic Christian experience of receiving communications from God. Mental Health, Religion \& Culture, 18, 97-113.

Dein, S., \& Littlewood, R. (2011). Religion and psychosis: A common evolutionary trajectory? Transcultural Psychiatry, 48, 318-335.

Exline, J. J., Yali, A. M., \& Sanderson, W. C. (2000). Guilt, discord, and alienation: The role of religious strain in depression and suicidality. Journal of Clinical Psychology, 56, 1481-1496.

Fetzer Institute \& National Institute on Aging Working Group. (1999). Multidimensional measurement of religiousness/spirituality for use in health research. Kalamazoo, MI: Fetzer Institute.

Freud, S. (1961). Obsessive actions and religious practices. In J. Strachey (Ed. \& Trans.), The standard edition of the complete psychological works of Sigmund freud (Vol. 9, pp. 167-175). London: Hogarth Press. (Original work published 1907)

Gale, J., Robson, M., \& Rapsomatioti, G. (Eds.). (2014). Insanity and divinity. Hove: Routledge.

Gearing, R. E., Alonzo, D., Smolak, A., McHugh, K., Harmon, S., \& Baldwin, S. (2011). Association of religion with delusions and hallucinations in the context of schizophrenia: Implications for engagement and adherence. Schizophrenia Research, 126, 150-163.

Gross, G., Huber, G., Klosterkötter, J., \& Linz, M. (2008). BSABS-Bonn Scale for the assessment of basic symptoms: manual, commentary, references, index, documentation Sheet (Berichte aus der Medizin). Aachen: Shaker Verlag.

Grover, S., Davuluri, T., \& Chakrabarti, S. (2014). Religion, spirituality, and schizophrenia: A review. Indian Journal of Psychological Medicine, 36, 119-124.

Hill, P. C. (2013). Measurement assessment and issues in the psychology of religion and spirituality. In R. F. Paloutzian \& C. L. Park (Eds.), Handbook of the psychology of religion and spirituality (pp. 48-74). New York, NY: The Guilford Press.

Huber, G., Gross, G., \& Schüttler, R. (1979). Schizophrenie. Eine Verlaufs- und Sozialpsychiatrische Langzeitstudie. Berlin: Springer.

Huguelet, P., Mohr, S., Borras, L., Gillieron, C., \& Brandt, P. Y. (2006). Spirituality and religious practices among outpatients with schizophrenia and their clinicians. Psychiatric Services, 57, 366-372.

Jackson, M. C., \& Fulford, K. W. M. (1997). Spiritual experience and psychopathology. Philosophy, Psychiatry and Psychology, 1, 41-65.

James, W. (1902). Varieties of religious experience. New York: Longmans, Green.

Jaspers, K. (1913). Allgemeine Psychopathologie: Ein Leitfaden für Studierende, Ärzte und Psychologen. Berlin: Springer.

Johnstone, B., Bodling, A., Cohen, D., Christ, S. E., \& Wegrzyn, A. (2012a). Right parietal lobe "selflessness" as the neuropsychological basis of spiritual transcendence. International Journal of the Psychology of Religion, 22, 267-284.

Johnstone, B., Cohen, D., Konopacki, K., \& Ghan, C. (2015). Selflessness as a foundation of spiritual transcendence: Perspectives from the neurosciences and religious studies. International Journal of the Psychology of Religion. doi:10.1080/10508619.2015.1118328.

Johnstone, B., Yoon, D. P., Cohen, D., Schopp, L. H., McCormack, G., Campbell, J., \& Smith, M. (2012b). Relationships among spirituality, religious practices, personality factors, and health for five different faith traditions. Journal of Religion and Health, 51, 1017-1041.

Johnstone, B., Yoon, D. P., Franklin, K. L., Schopp, L. H., \& Hinkebein, J. (2009). Reconceptualizing the factor structure of the brief multidimensional measure of religiousness/spirituality. Journal of Religion and Health, 48, 146-163. 
Kay, S. R., Fiszbein, A., \& Opler, L. A. (1987). The positive and negative syndrome scale (PANSS) for schizophrenia. Schizophrenia Bulletin, 13, 261-276.

Kéri, S., Kiss, I., Kelemen, O., Benedek, G., \& Janka, Z. (2005). Anomalous visual experiences, negative symptoms, perceptual organization and the magnocellular pathway in schizophrenia: a shared construct? Psychological Medicine, 35, 1445-1555.

Kirov, G., Kemp, R., Kirov, K., \& David, A. S. (1998). Religious faith after psychotic illness. Psychopathology, 31, 234-245.

Klosterkötter, J. (1988). Basissymptome und Endphänomene der Schizophrenie. Eine empirische Untersuchung der psychopathologischen Übergangsreihen zwischen defizitären und produktiven Schizophreniesymptomen. Berlin: Springer.

Klosterkötter, J., Ebel, H., Schultze-Lutter, F., \& Steinmeyer, E. M. (1996). Diagnostic validity of basic symptoms. European Archives of Psychiatry and Clinical Neuroscience, 246, 147-154.

Klosterkötter, J., Hellmich, M., Steinmeyer, E. M., \& Schultze-Lutter, F. (2001). Diagnosing schizophrenia in the initial prodromal phase. Archives of General Psychiatry, 58, 158-164.

Koenig, H. G. (2000). Religion and medicine I: historical background and reasons for separation. International Journal of Psychiatry in Medicine, 30, 385-398.

Koenig, H. G. (2007). Religion, spirituality and psychotic disorders. Revista De Psiquiatria Clínica, 34(Suppl 1), 40-48.

Kroll, J., \& Sheehan, W. (1989). Religious beliefs and practices among 52 psychiatric inpatients in Minnesota. American Journal of Psychiatry, 146, 67-72.

Larøi, F., Luhrmann, T. M., Bell, V., Christian, W. A, Jr, Deshpande, S., Fernyhough, C., et al. (2014). Culture and hallucinations: Overview and future directions. Schizophrenia Bulletin, 40(Suppl 4), S213-S220.

Larson, D. B., Pattison, E. M., Blazer, D. G., Omran, A. R., \& Kaplan, B. H. (1986). Systematic analysis of research on religious variables in four major psychiatric journals, 1978-1982. American Journal of Psychiatry, 143, 329-334.

Larson, D. B., Sherrill, K. A., Lyons, J. S., Craigie, F. C, Jr, Thielman, S. B., Greenwold, M. A., \& Larson, S. S. (1992). Associations between dimensions of religious commitment and mental health reported in the American Journal of Psychiatry and Archives of General Psychiatry: 1978-1989. American Journal of Psychiatry, 149, 557-559.

Littlewood, R., \& Dein, S. (2013). Did Christianity lead to schizophrenia? Psychosis, psychology and selfreference. Transcultural Psychiatry, 50, 397-420.

Matussek, P. (1987). Studies in delusional perception. In Cutting, J. \& Sheppard, M. (Eds.) Clinical roots of the schizophrenia concept. Translations of Seminal European Contributions on Schizophrenia (pp. 87-103). Cambridge: Cambridge University Press. (Original work was published in 1952).

McCarthy-Jones, S., Waegeli, A., \& Watkins, J. (2013). Spirituality and hearing voices: considering the relation. Psychosis, 5, 247-258.

Menezes, A., \& Moreira-Almeida, A. (2010). Religion, spirituality, and psychosis. Current Psychiatry Reports, 12, 174-179.

Miller, G. (2009). R.D. Laing and theology: The influence of Christian existentialism on "The Divided Self". History of Human Science, 22, 1-21.

Mishara, A. L., Lysaker, P. H., \& Schwartz, M. A. (2014). Self-disturbances in schizophrenia: History, phenomenology, and relevant findings from research on metacognition. Schizophrenia Bulletin, 40, $5-12$.

Mohr, S., Borras, L., Betrisey, C., Pierre-Yves, B., Gilliéron, C., \& Huguelet, P. (2010a). Delusions with religious content in patients with psychosis: How they interact with spiritual coping. Psychiatry, 73, $158-172$.

Mohr, S., Borras, L., Nolan, J., Gillieron, C., Brandt, P. Y., Eytan, A., et al. (2012). Spirituality and religion in outpatients with schizophrenia: A multi-site comparative study of Switzerland, Canada, and the United States. International Journal of Psychiatry in Medicine, 44, $29-52$.

Mohr, S., Borras, L., Rieben, I., Betrisey, C., Gillieron, C., Brandt, P. Y., et al. (2010b). Evolution of spirituality and religiousness in chronic schizophrenia or schizo-affective disorders: A 3-years followup study. Social Psychiatry and Psychiatric Epidemiology, 45, 1095-1103.

Mohr, S., Brandt, P. Y., Borras, L., Gilliéron, C., \& Huguelet, P. (2006). Toward an integration of spirituality and religiousness into the psychosocial dimension of schizophrenia. American Journal of Psychiatry, 163, 1952-1959.

Mohr, S., \& Huguelet, P. (2004). The relationship between schizophrenia and religion and its implications for care. Swiss Medical Weekly, 134, 369-376.

Murray, E. D., Cunningham, M. G., \& Price, B. H. (2012). The role of psychotic disorders in religious history considered. Journal of Neuropsychiatry and Clinical Neurosciences, 24, 410-426. 
Nelson, B., Whitford, T. J., Lavoie, S., \& Sass, L. A. (2014a). What are the neurocognitive correlates of basic self-disturbance in schizophrenia? Integrating phenomenology and neurocognition. Part 1 (Source monitoring deficits). Schizophrenia Research, 152, 12-19.

Nelson, B., Whitford, T. J., Lavoie, S., \& Sass, L. A. (2014b). What are the neurocognitive correlates of basic self-disturbance in schizophrenia? Integrating phenomenology and neurocognition. Part 2 (aberrant salience). Schizophrenia Research, 152, 20-27.

Nolan, J. A., McEvoy, J. P., Koenig, H. G., Hooten, E. G., Whetten, K., \& Pieper, C. F. (2012). Religious coping and quality of life among individuals living with schizophrenia. Psychiatric Services, 63, 1051-1054.

Oman, D. (2013). Defining religion and spirituality. In R. F. Paloutzian \& C. L. Park (Eds.), Handbook of the psychology of religion and spirituality (pp. 22-47). New York, NY: The Guilford Press.

Pargament, K. I. (2002). Is religion nothing but ...? Explaining religion versus explaining religion away. Psychological Inquiry, 13, 239-244.

Parnas, J., Handest, P., Saebye, D., \& Jansson, L. (2003). Anomalies of subjective experience in schizophrenia and psychotic bipolar illness. Acta Psychiatrica Scandinavica, 108, 126-133.

Postmes, L., Sno, H. N., Goedhart, S., van der Stel, J., Heering, H. D., \& de Haan, L. (2014). Schizophrenia as a self-disorder due to perceptual incoherence. Schizophrenia Research, 152, 41-50.

Rieben, I., Mohr, S., Borras, L., Gillieron, C., Brandt, P. Y., Perroud, N., \& Huguelet, P. (2013). A thematic analysis of delusion with religious contents in schizophrenia: Open, closed, and mixed dynamics. Journal of Nervous and Mental Disease, 201, 665-673.

Robertson, L. C. (2003). Binding, spatial attention and perceptual awareness. Nature Reviews Neuroscience, 4, 93-102.

Sass, L. (2001). Self and world in schizophrenia: Three classic approaches. Philosophy, Psychiatry and Psychology, 8, 251-270.

Sass, L. A., \& Parnas, J. (2003). Schizophrenia, consciousness, and the self. Schizophrenia Bulletin, 29, 427-444.

Sheehan, D. V., Lecrubier, Y., Sheehan, K. H., Amorim, P., Janavs, J., Weiller, E., et al. (1998). The MiniInternational Neuropsychiatric Interview (MINI): the development and validation of a structured diagnostic psychiatric interview for DSM-IV and ICD10. Journal of Clinical Psychiatry, 59(Suppl 20), $22-33$.

Siddle, R., Haddock, G., Tarrier, N., \& Faragher, E. B. (2002). Religious delusions in patients admitted to hospital with schizophrenia. Social Psychiatry and Psychiatric Epidemiology, 37, 130-138.

Silverstein, S. M. (1988). A study of religious conversion in North America. Genetic, Social, and General Psychology Monographs, 114, 261-305.

Silverstein, S. M. (2007). Integrating Jungian and self-psychological perspectives within cognitive-behavior therapy for a young man with a fixed religious delusion. Clinical Case Studies, 6, 263-276.

Silverstein, S. M. (2014). Jung's views on causes and treatments of schizophrenia in light of current trends in cognitive neuroscience and psychotherapy research I. Aetiology and phenomenology. Journal of Analytic Psychology, 59, 98-129.

Silverstein, S. M., \& Rosen, R. (2015). Schizophrenia and the eye. Schizophrenia Research Cognition, 2, 46-55.

Stanghellini, G., \& Fusar-Poli, P. (2012). The vulnerability to schizophrenia: Mainstream research paradigms and phenomenological direction. Current Pharmaceutical Design, 18, 338-345.

Stolz, J. (2008). The explanation of religiosity: Testing sociological mechanisms empirically. Lausenne: Observatoire des Religions en Suisse.

Szily, E., \& Kéri, S. (2009). Anomalous subjective experience and psychosis risk in young depressed patients. Psychopathology, 42, 229-235.

Taves, A. (2009). Religious experience reconsidered: A building-block approach to the study of religion and other special things. Princeton, NJ: Princeton University Press.

Verhagen, P., Van Praag, H.H., López-Ibor Jr, J.J., Cox, J., \& Moussaoui, D. (2010). Religion and psychiatry. Beyond boundaries. West Sussex: John Wiley \& Sons.

Wilson, W. P. (1998). Religion and psychoses. In H. G. Koenig (Ed.), Handbook of religion and mental health (pp. 161-173). San Diego, CA: Academic Press. 